\title{
THE USE OF GEOSTATIONARY BASED RAINFALL ESTIMATION FOR CHARACTERIZING STORM SEVERITY
}

\author{
SUSENO, Dwi Prabowo Yuga ${ }^{1,2}$, Tomohito J. YAMADA 3 \\ ${ }^{1}$ Member of JSCE, M.Sc., Doctoral Student, Graduate School of Engineering, Hokkaido University \\ (Kita 13, Nishi 8, Kita-ku, Sapporo, Hokkaido, 060-8628, Japan) \\ ${ }^{2}$ Watershed Management Office of Indragiri-Rokan, Ministry of Forestry, Republic of Indonesia \\ (Jl. H.R. Subrantas km 8,5 Pekanbaru, Riau, Indonesia) \\ ${ }^{3}$ Member of JSCE, PhD, Associate Professor, Faculty of Engineering, Hokkaido University \\ (Kita 13, Nishi 8, Kita-ku, Sapporo, Hokkaido, 060-8628, Japan)
}

\begin{abstract}
This research deals with the use of geostationary satellite based rainfall estimation for characterizing storm severity. The objectives of this research are to estimate storm rainfall intensity by using Multi-functional Transport Satellite (MTSAT) blended with C-band rainfall radar data and to show the severity of the identified storm rainfall intensity by representing its return period map. A regional frequency analysis (RFA) method developed by Hosking and Wallis (1997) is used to define the frequency distribution of long-term hourly maximum rainfall over Hokkaido Island. RFA indicates that Generalized Normal/Log Normal three parameters $(\mathrm{GNO} / \mathrm{LN} 3)$ is suitable to describe the frequency distribution of long-term hourly maximum rainfall over Hokkaido Island. Characterization of severity of 24 August 2010 storm event has been performed over Ishikari river basin, Hokkaido according to estimated rainfall using MTSAT data. Even though the return period map shows underestimation in comparison with the current situation of flood event in Ishikari river basin, this information is useful for flood control and mitigation.
\end{abstract}

Key Words : MTSAT, C-band radar, Rainfall estimation, Regional Frequency Analysis

\section{INTRODUCTION}

Evaluation of post extreme flood event is important regarding to disaster prevention and mitigation. Such evaluation can be accomplished by characterizing the severity of flood event such as by performing frequency analysis to quantify its return period. The flood's return period serves as the information for designing flood mitigation or flood control structures. However, the problem arises when there is no discharge available that corresponds to the event due to the damage of river measurement gauge caused by flash flood itself. To overcome such problem, rainfall frequency estimates are often used to describe the characteristics of flood events by calculating the return period of the greatest point rainfall intensity within the storm that is considered as the return period of the storm. ${ }^{1)}$ However, the characterization flood by rainfall information sometimes is hampered by the limited number of raingauge. Therefore, combining point measured raingauge data with spatially distributed rainfall estimation is of great advantage.

Meteorological satellite remote sensing technology plays an important role in providing rainfall information. The global coverage of the satellite makes its suitable for providing data for the regions, which lack rainfall gauge measurement. Moreover, satellite remote sensing has regular and repetitive data acquisition, which gives an advantage for environmental monitoring purpose.

The use of satellite remote sensing is also motivated by the occurrence of devastating hazard, triggered by severe rainfall events such as flash flood. Autoestimator ${ }^{2)}$ followed by Hydroestimator is geostationary satellite infrared based extreme rainfall algorithm that has been operationally used for flash flood monitoring in the US.

Long-term rainfall record from point measurement by raingauge is used to describe the frequency distribution of the location of gauge 
stations. Regional frequency analysis (RFA) such as developed by Hosking and Wallis ${ }^{3)}$ is mainly used to estimate the regional frequency distribution over a defined region. The appropriate extreme frequency distribution is used to assess the return period of the current extreme event that can be spatially monitored by remote sensing rainfall estimation. Some researchers have been using $\operatorname{radar}^{1)}$ and satellite rainfall information from Tropical Rainfall Measuring Mission (TRMM) ${ }^{4,5)}$. The return period information is very useful for characterizing the severity of extreme event such as storm ${ }^{1)}$.

This research deals with the use of geostationary satellite based rainfall estimation for characterizing storm severity. The objectives are threefold: (i) to estimate storm rainfall by using Multi-functional Transport Satellite (MTSAT) blended with C-band rainfall radar; (ii) to analyze the regional frequency hourly maximum rainfall; (iii) to show the severity of the identified storm rainfall by representing its return period map according to the regional frequency distribution.

\section{STUDY AREA AND DATA}

The study area is the whole Japan and its surrounding area where the coordinate boundary is between $30^{\circ} \mathrm{N}$ to $50^{\circ} \mathrm{S}$ and $120^{\circ} \mathrm{E}$ to $150^{\circ} \mathrm{E}$ (window size $20^{\circ} \times 30^{\circ}$ ). We focus on June - September 2010.

MTSAT data combined with C-band radar are employed to perform rainfall estimation. MTSAT images of the study area, covering study period were downloaded from website WebGMS-MTSAT/GMS (HIMAWARI) data processing on WWW, Earthquake Research Institute \& Institute of Industrial Science, University of Tokyo (http://webgms.iis.u-tokyo.ac.jp).

The rainfall dataset of the same time period was derived from raingauge as well as C-band radar (4 $8 \mathrm{GHz}$ frequency) acquired by Automated Meteorological Data Acquisition System (AMeDAS). The temporal resolution of MTSAT and C-band radar is 1 hour and 10 minutes respectively. Fig. 1 shows the coverage of rainfall estimation by using MTSAT and C-band radar.

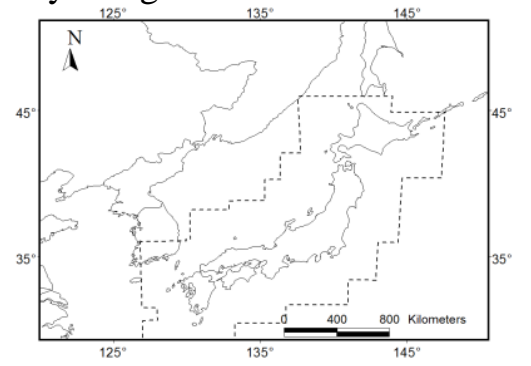

Fig.1 The study area shows Japan area and its surrounding. The dashed line is AMeDAS C-band radar network coverage boundary.
For the RFA purpose a long-term record of maximum yearly rainfall data over Hokkaido Island is used. In this case we use hourly rainfall data collected from 137 AMeDAS rainfall stations over Hokkaido Island during the period $1980-2010$ except for year 1989 and 2002 (28 years in total).

\section{METHODOLOGY}

The methodology of this research contains two main parts; the first satellite rainfall estimation by using MTSAT satellite datasets, and the second regional frequency analysis by using Hosking and Wallis method (1997). Fig. 2 shows the brief flow chart of the research and next section is the explanation of such diagram.

\section{(1) Satellite rainfall estimation}

The satellite rainfall estimation by using geostationary satellite is based on an indirect relationship between cloud top temperature depicted by infrared (IR-10.8 $\mu \mathrm{m}$ ) channel and rainfall rate (RR) derived by another devices. Misra et. al. uses IR data from Indian Satellite (INSAT-1D) and rainfall intensity form raingauge measurement to show the IR and RR relationship ${ }^{6}$. The combination of IR data from GOES image with rainfall radar is used by Autoestimator for storm rainfall estimation ${ }^{2)}$. The other research used the combination of both IR and RR from satellite information such as MSG with TRMM $^{7}$. In this study we use MTSAT IR channel 1 (IR1) dataset and C-band rainfall radar to derive cloud top brightness temperature and rainfall rate information respectively. Furthermore, we use additional information, i.e., cloud type which is included in the rainfall estimation process.

The relation uses an assumption where the colder temperature corresponds to heavier rainfall. However, this assumption is reasonable only for convective cloud type and relatively unreliable for other cloud types such as cirrus (cold but light or no rain) and Stratiform clouds (warm but wet) ${ }^{8}$. In this regard, cloud type classification is necessary to be performed to identify the distribution of convective storms rainfall ${ }^{9}$.

We use 2-dimensional (2-D) threshold diagram cloud type classification that based on MTSAT split window to conduct cloud type classification. There are two steps for threshold diagram classification i.e., cloud detection and cloud analysis. In the cloud detection by using MTSAT, we identify the cloud pixel based on the following relations: ${ }^{10)}$

Cloud over land: $\mathrm{IR}_{\text {clear }}-\mathrm{IR} 1>20 \mathrm{~K}$

Cloud over sea: $\mathrm{IR}_{\text {clear }}-\mathrm{IR} 1>7 \mathrm{~K}$ 


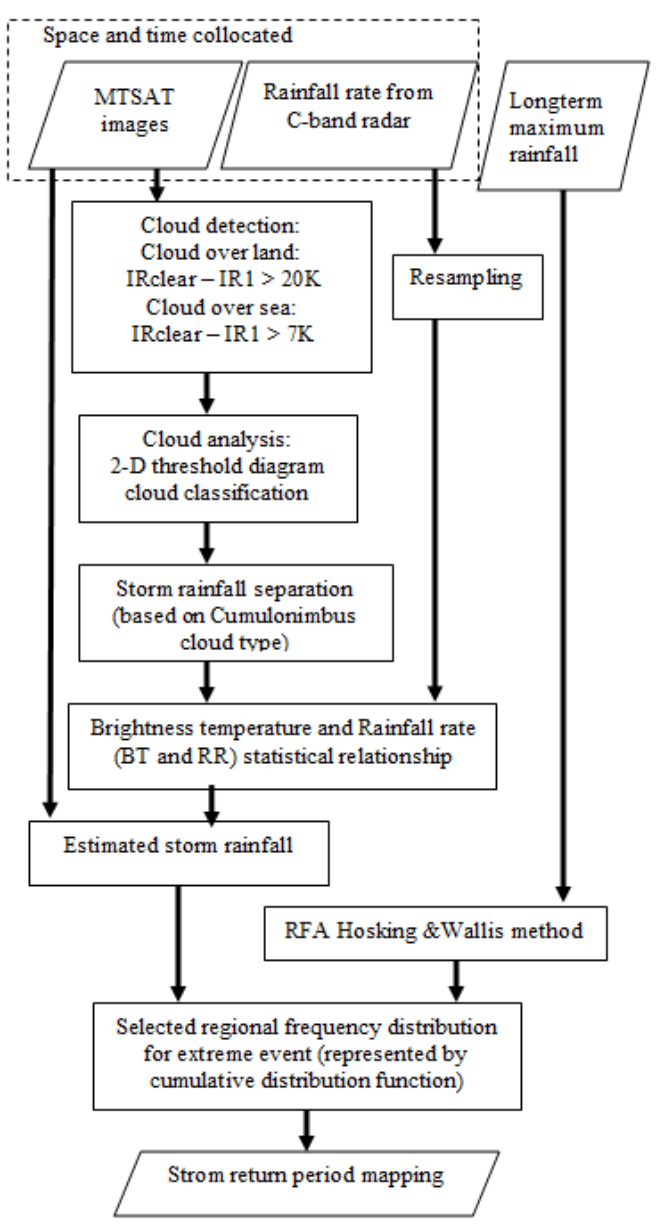

Fig.2 MTSAT based rainfall estimation and return period mapping methodology used in this study.

Where $I_{\text {clear }}$ and IR1 are the IR1 clear-sky brightness temperature and IR1 total-sky brightness temperature respectively. $I_{\text {clear }}$ is derived as the maximum value of all IR1 images during August 2010. The next step is cloud analysis by using the 2-D threshold diagram (see Fig. 3) to get the final result of cloud type classification. By using cloud type map resulted from the cloud classification, we separate Cumulonimbus ( $\mathrm{Cb}$ ) cloud type from the other types.

The C-band radar information that collocated at the same space and time with MTSAT image had been acquired. Based on collocated MTSAT and C-band rainfall radar, a pair of brightness temperature and rainfall rate (hereinafter BT and RR respectively) dataset can be generated. A regression line can be developed to represent the statistical relationship between $\mathrm{BT}$ and RR for storm rainfall estimation.

We develop some pairs of BT and RR according to the several storm events during the period of June - September 2010 and draw an average BB and RR regression line.

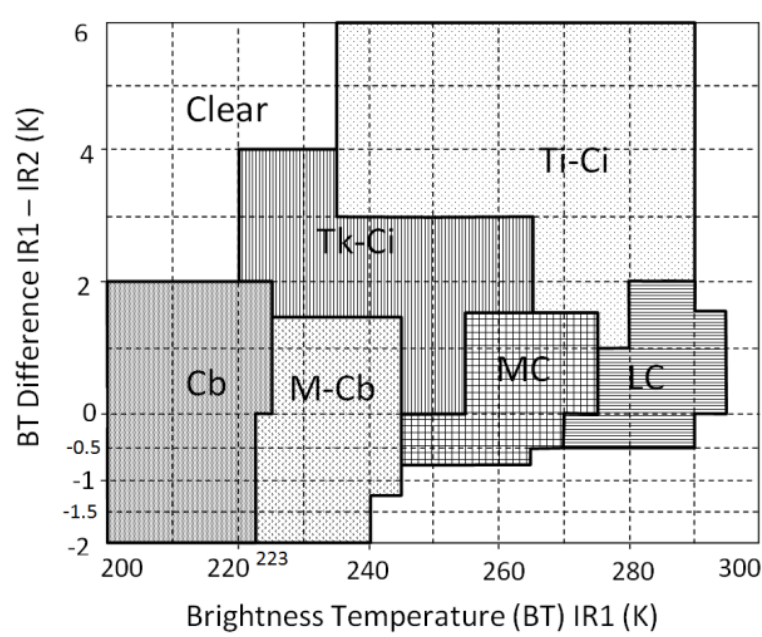

Fig.3 Two-dimensional threshold diagram for cloud type classification by using IR1 and BTD12 of MTSAT datasets. $^{9)}$

The rainfall estimation associated with such statistical relationship then will be validated by using raingauge measurement. Spatial validation by calculating spatial correlation will be performed for a selected storm event.

\section{(2) Regional Frequency Analysis}

Frequency analysis is the estimation of how often the specified event will occur. This is a tool for determining design rainfall or design discharge in a certain return period for the purpose of drainage work and structure. In the context of disaster management, frequency analysis is used for assessing the return period of an extreme event.

The conventional frequency analysis usually uses data derived from single station (e.g., one raingauge or one rivergauge). If there are many stations which are distributed within a suitably defined region, regional frequency analysis (RFA) should be used instead of the conventional frequency analysis. In this study, we use RFA method developed by Hosking and Wallis (hereinafter HW-RFA).

The first step of HW-RFA is data screening. The purpose of screening the data is to eliminate the gross error and inconsistencies and to check whether the data are homogeneous (stationary) over time. For screening the data, the discordancy measure $\left(D_{\mathrm{i}}\right)$ is used. The $D_{i}$ is defined by:

$$
D_{i}=\frac{1}{3}\left(u_{i}-\bar{u}\right)^{T} S^{-1}\left(u_{i}-\bar{u}\right)
$$

Where $u_{i}$ is the vector of L-moments, L-coefficient of variation $(\mathrm{LCv}), \mathrm{L}$-coefficient of skewness $(\mathrm{LCs})$ and L-coefficient of kurtosis (LCk) for a site $i$.

$$
S=\left(N_{s}-1\right)^{-1} \sum_{i=1}^{N_{s}}\left(u_{i}-\bar{u}\right)\left(u_{i}-\bar{u}\right)^{T}
$$




$$
\bar{u}=N_{s}^{-1} \sum_{i=1}^{N_{s}} u_{i}
$$

Where $\mathrm{N}_{\mathrm{s}}$ is the number of sites in the group. A site is denoted as discordant if $\mathrm{D}_{\mathrm{i}}>3$.

The next step is the identification of homogeneous region. Homogeneous region is considered as a set of sites whose frequency distributions are considered to be approximately the same. This 'region' is the fundamental unit of RFA. A heterogeneity measured is called $\mathrm{H}$-statistic. There are three heterogeneity measures called $\mathrm{H}_{1}$, $\mathrm{H}_{2}$ and $\mathrm{H}_{3}$ with respect to $\mathrm{LCv}$ scatter, $\mathrm{LCv}-\mathrm{LCs}$ and $\mathrm{LCv}-\mathrm{LCk}$ respectively. However $\mathrm{H}_{1}$ is commonly used. In general a region is declared 'acceptably homogeneous' if $\mathrm{H}_{1}<1$, 'possibly heterogeneous' if $1 \leq \mathrm{H}_{1}<2$, and 'definitely heterogeneous' if $\mathrm{H}_{1}>2$.

An appropriate frequency distribution is chosen by inspecting the goodness of fit between LCk versus LCs for various commonly used distributions duration with the corresponding relation obtained from the at site and regional data. This process is performed by using the Z-statistic as well as graphical method (LCs and LCk diagram).

\section{RESULTS AND DISCUSSIONS}

\section{(1) Rainfall estimation based on BT and RR} statistical relationship

During the period June - September 2010, we selected storm event cases by inspecting both raingauge measurement data as well as MTSAT image to select storm rainfall events. According to the inspection, we notify that storm events is strongly correspond to the distributed rainfall which is more than $30 \mathrm{~mm} / \mathrm{h}$. Based on such criterion, 20 storm events were selected. For each event we develop BT and RR pairs by using MTSAT and C-band radar and draw the statistical regression. In this study we use a modified exponential model to represent the statistical relationship. Furthermore, we reselect the events that show strong correlation between BT and RR finally obtain 10 storm events that have correlation coefficient ranging from $0.73-$ 0.92. According to those 10 storm events, an average $\mathrm{BT}$ and RR relationship is generated by using modified exponential regression model. The model is expressed by the following equation:

$$
\mathrm{RR}=0.0000061 \exp (3052.27 / \mathrm{BT}) \quad\left(\mathrm{r}^{2}=0.7\right)
$$

Where $\mathrm{RR}$ is estimated rainfall and $\mathrm{BT}$ is brightness temperature from MTSAT IR1. Fig. 4 shows the regression lines of average $\mathrm{BT}$ and $\mathrm{RR}$ relationship as well as the error bars.

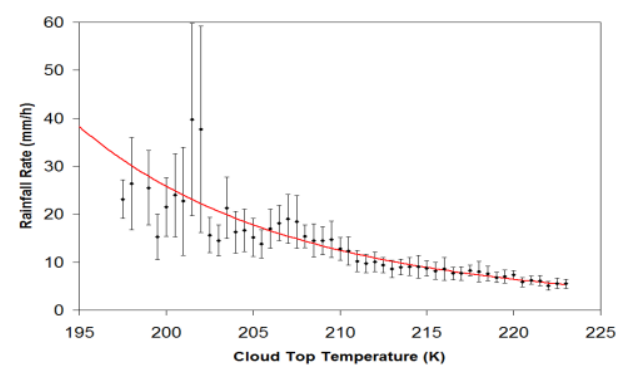

Fig.4 Cloud top brightness temperature and rainfall rate statistical relationship of storm rainfall events during June - September 2010 over Japan and its surrounding.

Fig. 4 show the deviation of rainfall rate became larger for lower cloud top temperature. The average deviation is about $7.7 \mathrm{~mm} / \mathrm{h}$, however there are several cases which have quite large deviation. A calibration process is necessary for future work.

By using the regression equation, the rainfall estimation based on MTSAT IR1 can be performed. Fig. 5a shows an example case of rainfall estimation result over Kyushu Island for a rainfall case on 22 June 2010 at 11:30 UTC. A validation has also been conducted by comparing rainfall estimation with measured rainfall over the same time and target region. Some point raingauge measurement had been spatially interpolated by using Block Kriging method and the result is presented in Fig. 5b. Both Fig. 5a and Fig. 5b show the comparison of rainfall estimation result with the measured rainfall (for land area). The spatial correlation is 0.79 and it confirms a good agreement between estimated and measured rainfall though according to Fig 5a, there are some location in the Kyushu Island where rainfall has been estimated, but actually there are no rain as shown for the same location in Fig $\mathbf{5 b}$.

\section{(2) RFA of Hokkaido Island}

The average value of long-term 1 hour maximum yearly rainfall is calculated for each station. Therefore, these values are interpolated by using inverse distance weight method for Hokkaido Island that is shown in Fig. 6a.
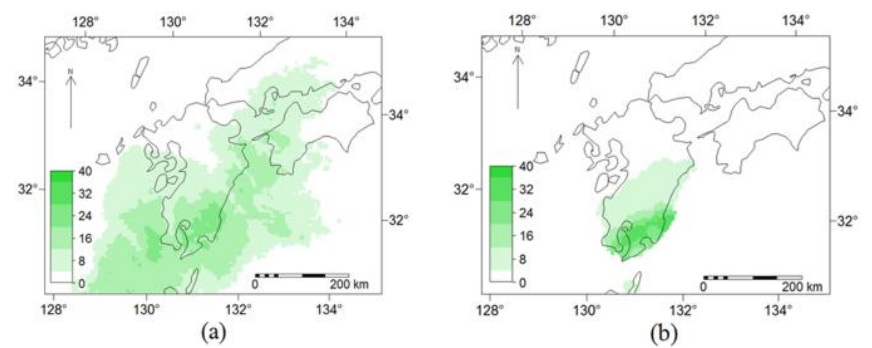

Fig.5 (a) Strom rainfall estimation distributions over Kyushu Island on 22 June 2010 at 11:30UTC. (b) rainfall distribution at the same location and time derived by spatial interpolation of point raingauge measurement. 
The distribution of this 1 hour long-term average maximum rainfall seems to be influenced by the topography since the western part has higher maximum rainfall than the eastern part which is clearly divided by the topography (see Fig. $\mathbf{6 b}$ ). The western and eastern region is denoted by sub region $\mathrm{A}$ and $\mathrm{B}$ respectively. These sub-regions are considered as 'the region' for RFA.

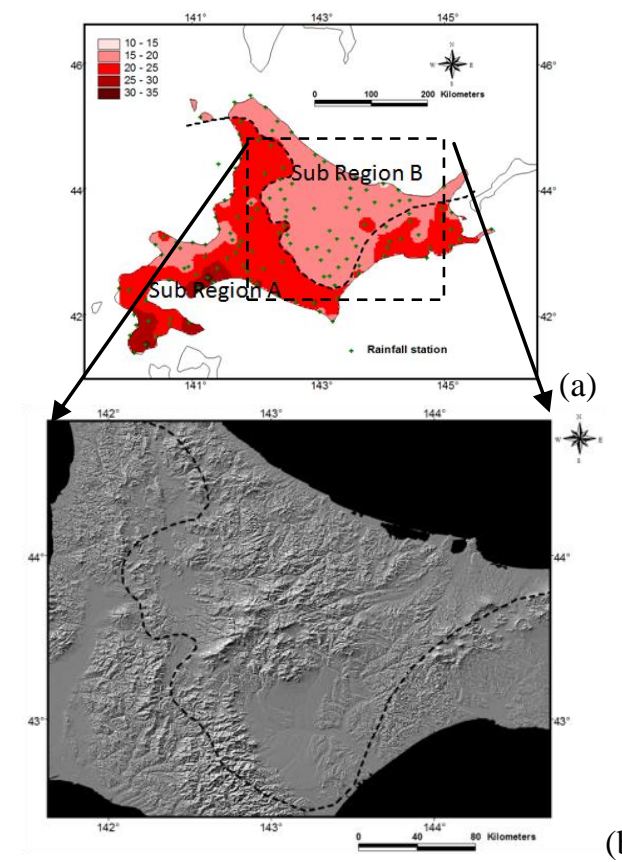

(b)

Fig.6 (a) Interpolation map of average of long-term maximum yearly rainfall (1 hour duration) by IDW method (b) shaded relief map represents the topography of Hokkaido Island.

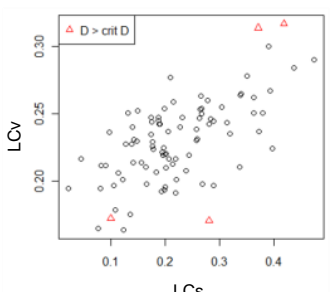

(a)

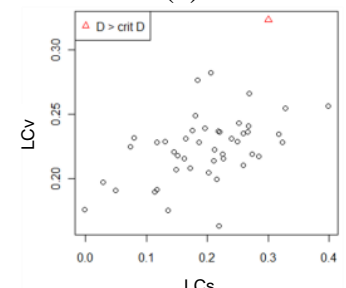

(c)

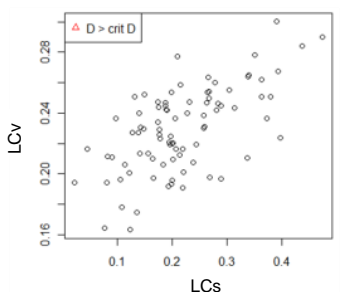

(b)

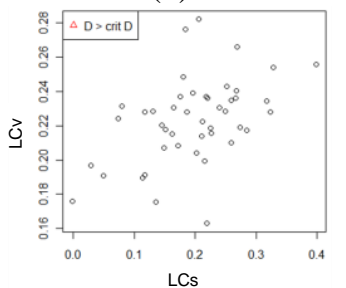

(d)
Fig.7 (a) and (c) discordancy diagram for Sub Region A and B respectively which represent discordant stations (D > 3) (denote by red triangle). (b) and (d) discordancy diagram for Sub Region A and B respectively after removing discordant stations which are use for determining frequency distribution.
The result of screening data shows that there are 4 and 1 stations in sub region A and B respectively which are discordant (see Fig. 7).

The heterogeneity measure confirms that the $\mathrm{H}_{1}$ -statistic are -1.53 and -1.89 for sub region $\mathrm{A}$ and $\mathrm{B}$ respectively. Those of $\mathrm{H}_{1}$ values are less than 1 which means both sub region is acceptably homogeneous.

Table 1. MTSAT based rainfall estimation and return period mapping methodology used in this study.

\begin{tabular}{|c|c|c||}
\hline Frequency Dist & Sub Region A & Sub Region B \\
\hline \hline GLO & 6.10 & 3.56 \\
GEV & 2.10 & 0.34 \\
GNO & $\mathbf{0 . 8 6}$ & -0.35 \\
PE3 & -1.54 & -1.84 \\
GPA & -7.31 & -6.96 \\
\hline
\end{tabular}

Choice of frequency distribution is conducted by calculating Z-statistic for five candidate of three parameters frequency distribution i.e. Generalize Logistic (GLO), Generalize Extreme Value (GEV), Generalize Normal (GNO) or Log Normal-three parameters (LN3), Log Pearson III (PE3) and Generalize Pareto (GPA). The Z-statistics value of those frequency distribution for sub region $\mathrm{A}$ and $\mathrm{B}$ is shown in Table 1. Considering the fit of distribution is satisfactory if $|Z|<1.64$, it confirms that GNO/PE3 distribution is suitable for both region A and B (see the bold value in Table1). Fig. $\mathbf{8 a}$ and $\mathbf{8 b}$ show the identification of regional frequency distribution using HW-RFA moment ratio LCs LCk diagram for sub region A and B. The red dots denote the position of the value of regional LCs LCk for the respective regions.

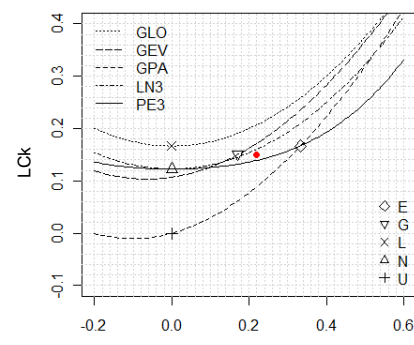

(a)

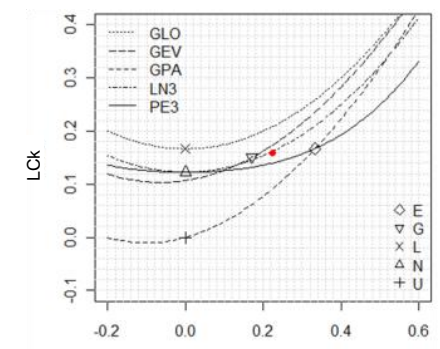

(b)
Fig.8 Identification of regional frequency distribution using HW-RFA moment ratio LCs LCk diagram ${ }^{8)}$ for (a) Sub Region A and (b) Sub Region B.

\section{(3) Strom severity characterization by return period mapping}

On 23-24 August 2010, it was reported that a storm event attacked the centre of Hokkaido Island from midnight until early morning ${ }^{11)}$. The amount of rainfall reported by The Sapporo District Meteorological Observatory is $42 \mathrm{~mm} / \mathrm{h}$. The heavy 
rainfall over Ishikari river basin caused floods and landslides. Two people were reported to have died in this disaster.

Here, we apply the GNO/LN3 distribution to characterize such storm event. Fig. 9a shows the spatial distribution of estimated rainfall derived by BT and RR relationship over Ishikari river basin during such storm event at 5:00 PM local time. The highest rainfall estimated within the Ishikari river basin is about $16 \mathrm{~mm} / \mathrm{h}$. Furthermore return period map is generated for this rainfall data, based on the GNO/LN3 distribution. The calculated return period is presented in Fig. 9b. It shows that the maximum return period for this case is 5 year which corresponds with the maximum estimated rainfall.

The rainfall estimation as well as the calculated return period seems underestimated when compared with the reported storm event. It is most probably because both rainfall estimation and the calculated return period are considered as snapshot events. Nevertheless, spatial distribution of return period serves as an important information that represents the severity of extreme event which is useful in for flood control and mitigation.

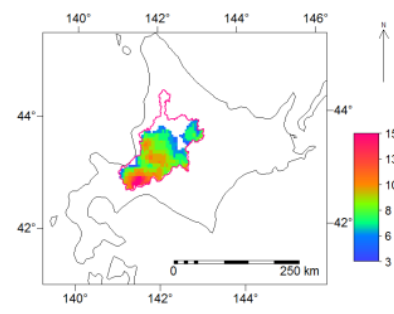

(a)

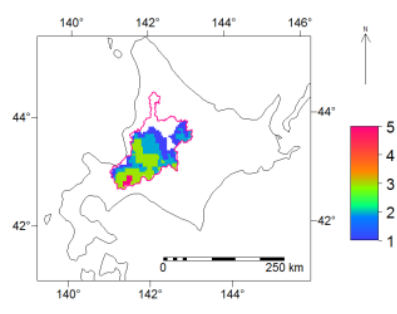

(b)
Fig.9 (a) Strom rainfall estimation distribution (in $\mathrm{mm}$ ) over Ishikari river basin on 24 August 2010 at 15:30UTC (b) return period map (in year) of corresponding storm rainfall event.

\section{CONCLUSIONS}

In this study, the rainfall estimation is conducted for Japan area and its surrounding by using BT and RR relationship. Those $\mathrm{BT}$ and $\mathrm{RR}$ are derived from MTSAT IR1 and C-band rainfall radar respectively. Storm severity analysis is performed in Ishikari river basin especially for 24 August 2010 storm event. The BT and RR relationship shows the deviation of RR became larger for lower BT. The average deviation is about $7.7 \mathrm{~mm} / \mathrm{h}$, therefore a calibration analysis is need for future work. However a validation over Kyushu Island rainfall case shows promising result. RFA indicates that GNO/LN3 distribution is suitable to describe the frequency distribution of maximum rainfall event in two sub regions in Hokkaido Island. Even though the return period is underestimated compared with the current situation of flood event in the Ishikari river basin, this information is useful in for flood control and mitigation.

ACKNOWLEDGMENT: This study was partially supported by the Research Program on Climate Change Adaptation, Ministry of Education, Culture, Sports, Science and Technology (RECCA/MEXT), and by the Science and Technology Research Partnership for Sustainable Development, JST-JICA, Japan.

\section{REFERENCES}

1) Norbiato, Daniele, M. Borga, M. Sangati, F. Zanon.: Regional frequency analysis of extreme precipitation in the eastern Italian alps and the August 29, 2003 flash flood, Journal of Hydrology 345, pp. 149 - 166, 2003

2) Vicente, Gilberto A., R. A. Scofield, W. P. Menzel.: The Operational GOES Infrared Rainfall Estimation Technique, BAMS Vol. 79, No.9 pp.1883 - 1898, 1998

3) Hosking, J.R.M., J. R. Wallis.: Regional Frequency Analysis. Cambridge University Press, p.224, 1997

4) Edreny, Theodore A., N. Imbeah. Generating robust rainfall intensity-duration-frequency estimates with short record satellite data, Journal of Hydrology 371, pp. 182 - 191, 2009

5) Awadallah, Ayman G., M. ElGamal, A. ElMostafa, H. ElBadry.: Developing intensity-duration-frequency curves in scarce data region: An approach using regional analysis and satellite data, Engineering, 3, pp. 215 - 226, doi: 10.4236/eng.2011.33025, 2011

6) Misra, J.K. and O.P. Sharma: Cloud top temperature based precipitation instensity estimation using INSAT-1D data. IJRS, 22(6), pp. 969 - 985, 2001

7) Jennifer, K., Z. Su, T. Woldai, B. Maathuis: Estimation of spatial-temporal rainfall distribution using remote sensing techniques: A case study of Makanya catchment, Tanzania. Int. J. of App. Earth Obsv. and Geoinfo. 12S , pp. S90 S99, 2010

8) Kuligowski, R.: Remote Sensing in Hydrology, From: http://www.weather.gov/iao/InternationalHydrologyCourse CD1/1029/wmo_bk.ppt, Retrieved: 4 November 2007.

9) Suseno, D. P. Y., Tomohito. J. Yamada.: The Use of Cloud Type Classification To Improve Geostationary Based Rainfall Estimation, The 9th International Symposium on Southeast Asian Water Environment, Dec $1^{\text {st }}-3^{\text {rd }} 2010$ Bangkok City, Thailand (Accepted)

10) Choi, Yong-San and Ho Chang Hoi.: Validation of cloud property retrievals from MTSAT-1R imagery using MODIS observations. IJRS, 30(22), pp. 5935 - 5958, 2009

11) Yamada, Tomohito. J. and J. Sasaki.: Characteristics of line-shape rainbands over Hokkaido in large meteorological field (In Japanese), Proceedings of 2011 JSHWR Annual Conference, 2011

(Received September 30, 2011) 